\title{
Method for Evaluation and Application of Production Process Chain Complexity in Sewing Workshops considering Human Factor
}

\author{
Huimin Li $\mathbb{D}$, ${ }^{1,2}$ Fansen Kong $\mathbb{i},{ }^{1,2,3}$ Taibo Chen $\mathbb{D},,^{2,4}$ and Liang Kong $\mathbb{D}^{2,5}$ \\ ${ }^{1}$ School of Mechanical and Aerospace Engineering, Jilin University, Changchun 130025, China \\ ${ }^{2}$ Jilin Provincial Key Laboratory of Designing and Planning for Factory, Jilin University, Changchun 130022, China \\ ${ }^{3}$ Key Laboratory of CNC Equipment Reliability, Ministry of Education, Jilin University, Changchun, Jilin, China \\ ${ }^{4}$ School of Management, Jilin University, Changchun 130025, China \\ ${ }^{5}$ Warwick Business School, University of Warwick, Coventry CV4 7AL, UK \\ Correspondence should be addressed to Fansen Kong; kongfs@jlu.edu.cn
}

Received 30 May 2021; Accepted 19 January 2022; Published 23 February 2022

Academic Editor: Sheng Du

Copyright (c) 2022 Huimin Li et al. This is an open access article distributed under the Creative Commons Attribution License, which permits unrestricted use, distribution, and reproduction in any medium, provided the original work is properly cited.

\begin{abstract}
Existing methods for evaluating manufacturing process chain complexity consider the number of machines, state of machines, number of parts, operation time, and processing sequence of parts. However, such evaluation methods ignore human factors. To consider human factors, human cognitive decision-making process factors are considered in the complexity evaluation of production processes. Accordingly, a new objective evaluation method of the human factor complexity is proposed. In the proposed method, sewing operations are taken as an example, and the human factor complexity is classified into perceived and cognitive complexity. Information entropy is used to measure cognitive complexity according to the type and quantity of sewing workers' cognitive activities. The results show that various methods have significant differences in the evaluation of the complexity level of the production process chain. Specifically, the calculation results of the proposed evaluation method are much greater than those of other methods. This indicates that human cognitive and perceived complexities account for a large proportion. Therefore, human factor complexity cannot be omitted.
\end{abstract}

\section{Introduction}

Currently, the applications of manufacturing system complexity are an active research area. However, complexity has no clear definition [1]. Scholars have defined manufacturing system complexity from different perspectives [2]. Isik [3] argued that complexity may have adverse effects, such as high operating costs, delivery delays, and inventory shortages. Complexity also negatively impacts the attributes of manufacturing systems, such as productivity [4], profit [5], and quality [6]. The research on the complexity of manufacturing systems mainly focuses on processing and assembly. Processing is the process of machining raw materials and semifinished products into target requirements through certain processes and methods. Processing complexity is usually divided into static complexity and dynamic complexity. Static complexity is structural complexity, which is related to the structure and configuration of manufacturing systems. It includes various elements such as people, machines, cache, logistics, and the relationship among them. Dynamic complexity refers to the uncertain factors and system probability in a specific period, such as the adjustment of a plan, change in the order, and task deviation [7]. Frizelle and Woodcock [2] were the first to use information entropy to evaluate manufacturing system complexity. However, there is no in-depth analysis of applicability and effectiveness with respect to complexity. Deshmukh [8] used information entropy to evaluate structural complexity and provided the basis for static and dynamic complexity evaluation. Modrak and Zuzana [9] 
proposed a method for evaluating static complexity and analysed the complexities of two different manufacturing layouts using the method. This method mainly considered factors such as equipment, parts, and processing sequences, but human factors were ignored. Zhang [10] proposed a method for evaluating static complexity by considering the system's structure and components based on information entropy. Zhang et al. [11] established the static and dynamic entropy models of a cell manufacturing system to reduce its structural complexity. Most of these studies developed complexity models and evaluation methods by describing the state of a manufacturing system. However, manufacturing systems are complex and dynamic; therefore, a method to accurately describe the actual state of a system still needs further research. Complexity theories are most widely used in assembly. As assembly is the final process of a manufacturing system, assembly workers need to complete assembly tasks within a limited time. The complexity of the assembly process is mainly related to uncertainty, work content, and time pressure [12]. It is also related to the diversity of products or parts under a customised production mode $[6,13]$. The complexity caused by product diversity and operation complexity in assembly has been the focus of various studies. Falck et al. [14] proposed the basic criteria of assembly system complexity evaluation from 16 dimensions, such as material, operation instruction, and operation time. However, these basic criteria mainly consider objective factors. He et al. [15] proposed a method for modelling and evaluating the structural complexity, process complexity, and operation complexity of an assembly system, but this method only analyses the simple mixed flow assembly system. Zhu et al. [16] proposed a measurement method of operator selection complexity, mainly considering product diversity and information in the assembly process, and developed a complexity model of a multilevel mixed-model assembly system suitable for serial structures. This mathematical model reveals the propagation mechanism of complexity in multilevel mixed-model assembly systems. Based on the modular arrangement of predetermined time standards (MOD method), Alkan et al. proposed a method to measure the operation complexity of a manual assembly system from three aspects, namely, action effort, operation diversity, and operation scale, and verified the effectiveness of this method through simulation [17]; however, the actual case was not analysed. Zaeh et al. [18] argued that workers' participation in a task is based on three interrelated factors, namely, time, cognition, and knowledge. However, the knowledge and cognitive factors still need to be further adjusted to ensure that they are applicable to any assembly operation. As the garment industry belongs to the fast fashion industry, it is characterized by multiple varieties and small batches. The garment production is still labor-intensive and the production process is highly complex. Weaving production has the characteristics of processing and assembly, which requires high technical level of sewing workers. Sewing is an important part of the weaving production system. During the sewing process, the sewing worker works synchronously with the machine, and the sewing worker plays a leading role in the production process.
In weaving production system, weaving complexity has an important impact on production efficiency and product quality. However, little is known about the effect of weaving complexity on task performance. The research results of manufacturing system complexity based on process or assembly cannot be directly applied to the field of weaving. To address this, in this study, a new production process complexity measurement method with both processing and assembly characteristics is developed to provide theoretical support for improving the production management and decision-making level of garment weaving industry.

\section{Related Studies}

Complexity measurement is the basis for managing and controlling complexity. Every manufacturing company should have the most appropriate level of complexity. Before adjusting the level of complexity to an appropriate or ideal level, it is necessary to measure the complexity [19-21]. However, the quantification of complexity is difficult [21]. Brinzer and Schneider [23] classified the measurement methods of manufacturing system complexity into two types: objective and subjective complexity measurements. Objective complexity considers the measurement of the internal factors of a manufacturing system, such as the configuration and structure of the system. Objective complexity is measured using information entropy [2], mathematical modelling [24], and information technology [25]. Subjective complexity measurement considers human factors, such as human perception and cognitive complexity. The methods for measuring subjective complexity are information entropy [26] and questionnaire methods [27], as shown in Figure 1.

Information entropy is frequently used to evaluate manufacturing system complexity. The existing methods for assessing production process chain complexity are as follows.

Method 1 (static complexity evaluation method proposed by Deshmukh et al. [24]): this method is relatively simple. It considers three parameters of a manufacturing system, namely, the number of machines, number of operations, and number of parts. Its formula is as follows [24]:

$$
C_{s 1}=\log _{2} m^{2} n r,
$$

where $r, m$, and $n$ represent the numbers of machines, operations, and parts, respectively.

Method 2 (static complexity evaluation method proposed by Frizelle and Woodcock [2]): this method uses information entropy to evaluate static complexity. However, it only considers the processing state of machines. When the machine processes different parts, it is regarded to be in different states. Its formula is as follows [2]:

$$
C_{s 2}=-\sum_{j=1}^{M} \sum_{i=1}^{S_{j}} P_{i j} \log _{2} P_{i j},
$$

where $M$ represents the number of machines, $S_{j}$ represents the number of possible planned states of the $j$ th machine can be in, and $P_{i j}$ represents the possibility that the $j$ th machine 


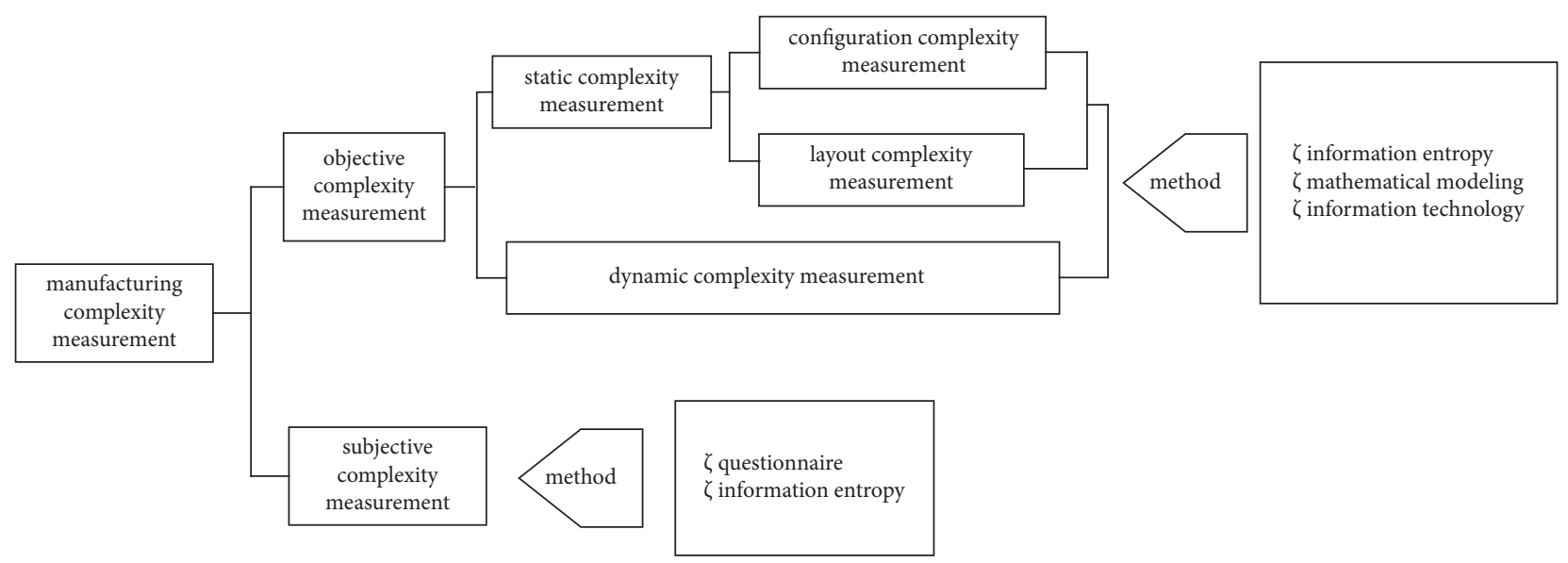

FIgURE 1: Content and methods of complexity measurement of the manufacturing system.

is in state $i$. In other words, $P_{i j}$ is expressed as the ratio of the machine operation time to the production cycle.

Method 3 (static complexity evaluation method proposed by Zhang [10]): this method also uses information entropy to evaluate the static complexity of a manufacturing system. In this method, the processing and idle states of the machine are considered. However, similar to Method 2, when different machines process different parts, they are regarded to be in different states. Its formula is as follows [10]:

$$
C_{s 3}=-\sum_{j=1}^{M} \sum_{i=1}^{S_{j}} P_{i j} \log _{2} P_{i j}
$$

where $M$ represents the number of machines, $S_{j}$ represents the number of possible planned states of the $j$ th machine can be in, and $P_{i j}$ represents the possibility that the $j$ th machine is in state $i$. Method 4 (static complexity of a manufacturing process chain considering the processing sequence [8]): this method considers the processing sequence of parts based on two assumptions. First, in the manufacturing process chain, machines are usually arranged in series or parallel. According to the two layouts, the probability of the $k$ th part being processed on the $j$ th machine is expressed as $P_{j k}$. Second, when the part is processed on a serial machine, the value of $P_{j k}$ is $1 / M_{\mathrm{S}}$, where $M_{\mathrm{S}}$ is the number of serial machines. When the part is processed on a parallel machine, the value of $P_{j k}$ is $1 / M_{\mathrm{P}}$, where $M_{P}$ is the number of parallel machines. When the part is processed on a parallel machine with a serial/parallel mixed layout, $P_{j k}$ is expressed as $1 /\left(M_{S} M_{P}\right)$. Its formula is as follows [9]:

$$
C_{s 4}=-\sum_{j=1}^{M} \sum_{k=1}^{N} P_{j k} \log _{2} P_{j k}
$$

where $P_{j k}$ expresses the probability that the $k$ th part is processed on the $j$ th machine, according to the processing sequence of the parts. $N$ represents the number of parts processed in the manufacturing process chain, and $M$ represents the number of machines involved in the manufacturing process chain.
A summary of the aforementioned evaluation methods is provided in Table 1.

\section{Method for Evaluating Sewing Process Chain Complexity considering Human Factors}

Based on Method 4, we evaluate the manufacturing process chain complexity of garment production considering human factors. Because sewing plays a crucial role in garment production, we mainly discuss the method for evaluating sewing production process chain complexity. The evaluation framework is shown in Figure 2.

The perception and cognitive complexities are mainly discussed when considering human factors. The perception and cognitive processes can be regarded as processes of information processing, as shown in Figure 3. The information input is considered a perception process and considers the relationship among products, tools, processes, and work areas. Information processing and information output are classified as cognitive processes. The cognitive process has four cognitive functions based on the second-generation human reliability analysis method: observation, interpretation, planning, and execution. These cognitive functions correspond to 15 cognitive activities. According to the types and quantity of cognitive activities corresponding to sewing operations, information entropy is used to evaluate cognitive complexity. The flow chart of the human factor complexity evaluation is shown in Figure 4.

\subsection{Method for Evaluating the Perceived Complexity of Sewing} Workers. In the garment production process, information input is classified as a perception process. Sewing workers' perception of information is influenced by many factors, such as the quantity and diversity of information [26]. The production process mainly involves four types of information: product information $(X 1)$, process information $(X 2)$, tools and equipment information (X3), and workplace information $(X 4)$. For any information variable $X$, which has $n$ possible values $(Y 1, Y 2, \ldots, Y n)$, we assume that the information variables have specific relationships 
TABLE 1: Summary of methods for evaluating manufacturing process chain complexity.

$\begin{aligned} & \text { Evaluation } \\ & \text { method }\end{aligned}$
$\begin{aligned} & \text { Input parameters } \\ & \text { Method } 1\end{aligned}$
$\begin{aligned} & \text { The number of machines and the state of machines (only the processing state is considered) } \\ & \text { Method } 3\end{aligned}$
Tethod 4
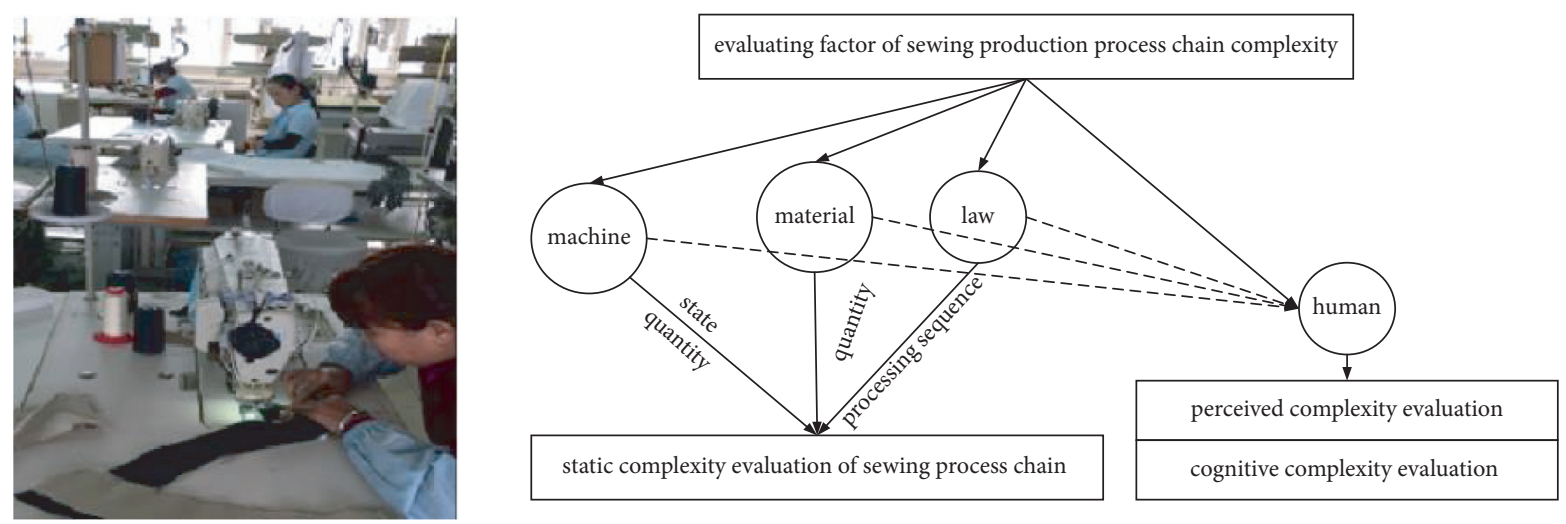

FIGURE 2: Evaluation framework of sewing process chain complexity.

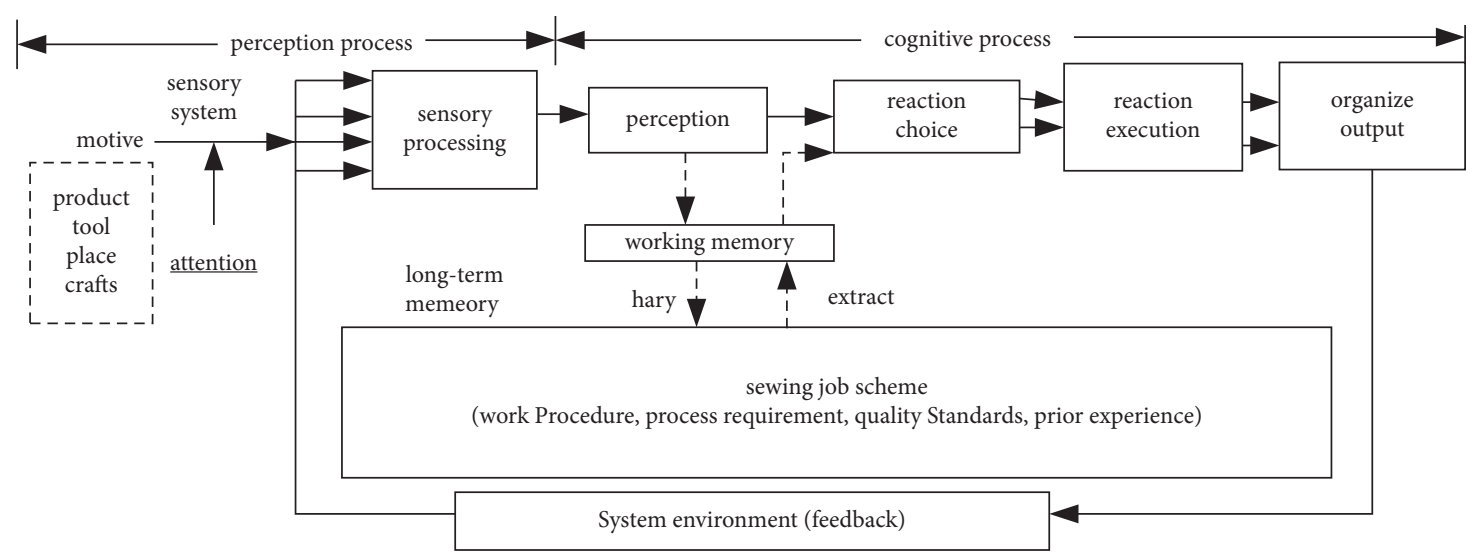

FIGURE 3: Model of sewing operation information process.

among them, such as calling, being-called, self-relation, and no-relation. The relationship can be defined as $R=$ (self-relation, calling, being-called, no-relation $)=(1,1,1$, $0) . R_{i j}\left(i=1,2, \ldots, n_{j} ; j=1,2,3,4\right)$ represents the relationship between a perceived information variable and other perceived information variables. According to Kong (2018), the formula for calculating the perception complexity of the $m$ th sewing process is expressed as follows [26]:

$$
C_{p m}=-\sum_{j=1}^{4} \sum_{i=1}^{n_{j}} P_{i j} \log _{2} P_{i j}
$$

where

$$
\begin{gathered}
P_{i j}=\frac{R_{i j}}{R_{j}}, \\
R_{j}=\sum_{i=1}^{n_{j}} R_{i j} .
\end{gathered}
$$

3.2. Method for Evaluating the Cognitive Complexity of Sewing Workers. The cognitive process involves information processing and information output based on the process shown in Figure 3. The second-generation human reliability analysis method classifies cognitive functions into four categories: observation, interpretation, planning, and 


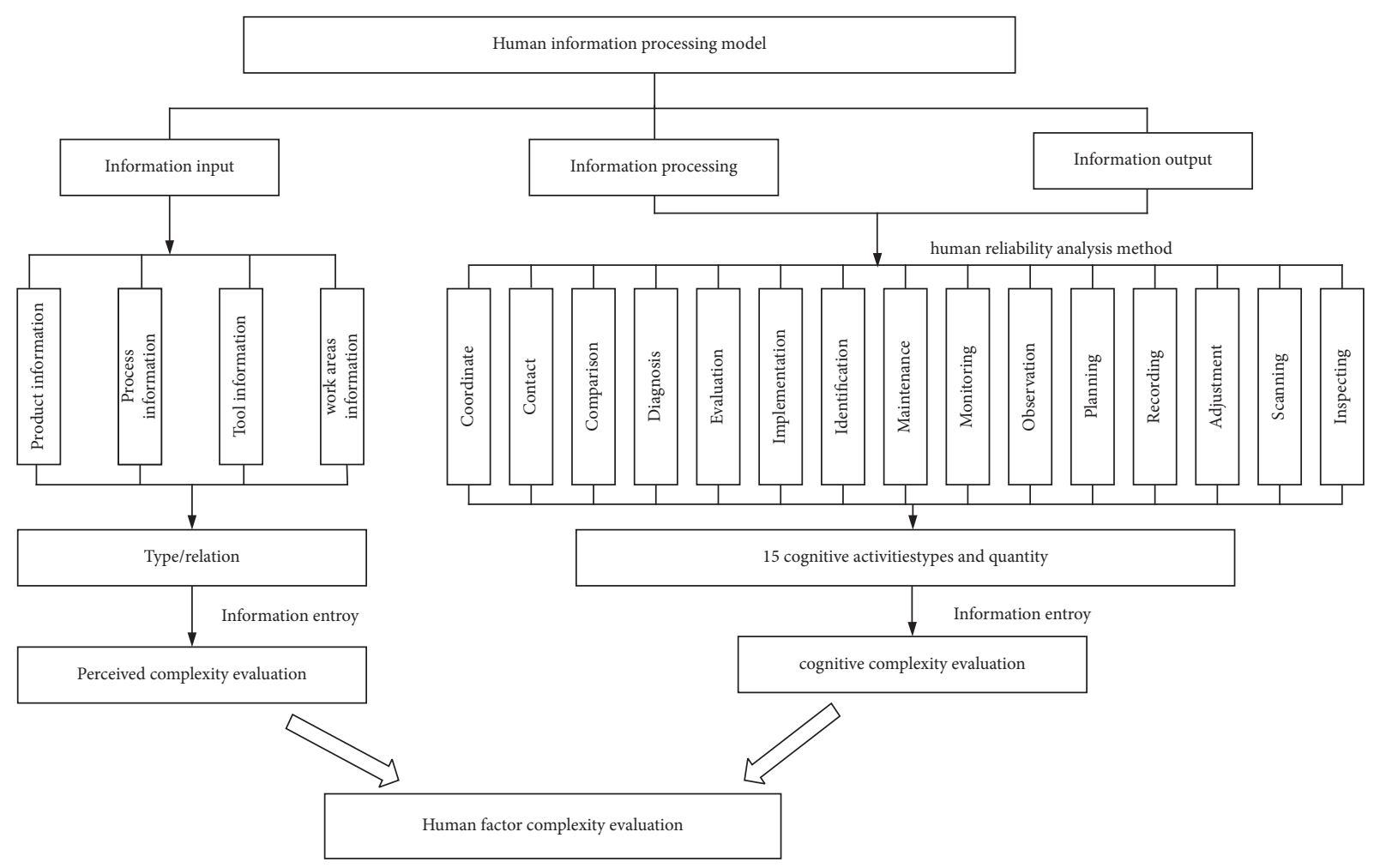

Figure 4: Flow chart of the human factor complexity evaluation.

execution. These cognitive functions can be further divided into 15 cognitive activities: coordination, contact, comparison, diagnosis, evaluation, identification, implementation, maintenance, monitoring, observation, planning, recording, adjustment, scanning, and inspection. When any cognitive activity belongs to any cognitive function, it is represented by " $\sqrt{ }$." The corresponding relationship among them is shown in Table 2.

$s$ is used to indicate work step. The $m$ th sewing process is decomposed into $n_{s}$ work steps. According to the secondgeneration human reliability analysis method, the type of cognitive activity and cognitive function are judged for each work step, $\mathrm{CO}_{\text {saf }}$ represents the ath cognitive activity and the $f$ th cognitive function of the sth work step, as shown in Table 3. According to Table 2, when the sth work step is judged as the ath cognitive activity and this cognitive activity belongs to the $f$ th cognitive function, $C O_{s a f}=1$; otherwise, $C O_{s a f}=0 . C O_{f}$ represents the sum of the ath cognitive activity and this cognitive activity belongs to the $f$ th cognitive function. $P_{c o f}$ represents probability of the $f$ th cognitive function in the $m$ th sewing process. According to Table 3, cognitive complexity of the $m$ th sewing process is quantified using information entropy, which can be expressed as follows:

$$
C_{c m}=-\sum_{f=1}^{4} P_{c o f} \log _{2} P_{c o f}
$$

3.3. Method for Evaluating Sewing Production Process Chain Complexity. Based on the aforementioned qualified method, the sewing production process chain complexity is defined and quantified as follows:

$$
C_{l}=C_{s 4}+C_{g}+C_{r},
$$

where

$$
\begin{aligned}
& C_{p}=\sum_{m=1}^{n_{p}} C_{p m}, \\
& C_{c}=\sum_{m=1}^{n_{c}} C_{c m} .
\end{aligned}
$$

$n_{p}$ represents the number of perceived complexities. $n_{c}$ represents the number of cognitive complexities.

3.4. Case Analysis of the Sewing Process Chain Complexity Evaluation. Currently, most garment production enterprises adopt the bundle mode. Owing to the increasing demand for multiple varieties and small batches, the complexity continues to increase. In production workshops, each cut piece is processed according to an arranged order. Sewing workers and machines work synchronously. Particularly, sewing workers play a significant role in ensuring efficiency and quality. Therefore, throughout the evaluation of the sewing production process chain complexity, we must consider the processing sequence of cut pieces and human factors. In this study, we investigate garment enterprise A and adopt the production process of a women's clothing workshop as an example. We use the 
TABLE 2: Corresponding relationship of cognitive activity and cognitive function.

\begin{tabular}{|c|c|c|c|c|c|}
\hline \multirow{2}{*}{ Cognitive activity } & \multicolumn{5}{|c|}{ Cognitive function } \\
\hline & Denotation & Observation & Explanation & Plan & Execution \\
\hline Coordinate & Ca1 & & & $\sqrt{ }$ & $\sqrt{ }$ \\
\hline Contact & $\mathrm{Ca} 2$ & & & & $\sqrt{ }$ \\
\hline Comparison & $\mathrm{Ca} 3$ & & $\sqrt{ }$ & & \\
\hline Diagnosis & $\mathrm{Ca} 4$ & & $\sqrt{ }$ & $\sqrt{ }$ & \\
\hline Evaluation & $\mathrm{Ca} 5$ & & $\sqrt{ }$ & $\sqrt{ }$ & \\
\hline Implementation & $\mathrm{Ca} 6$ & & & & $\sqrt{ }$ \\
\hline Identification & $\mathrm{Ca} 7$ & & $\sqrt{ }$ & & \\
\hline Maintenance & $\mathrm{Ca} 8$ & & & $\sqrt{ }$ & $\sqrt{ }$ \\
\hline Monitoring & $\mathrm{Ca} 9$ & $\sqrt{ }$ & $\sqrt{ }$ & & \\
\hline Observation & $\mathrm{Ca} 10$ & $\sqrt{ }$ & & & \\
\hline Planning & Ca11 & & & $\sqrt{ }$ & \\
\hline Recording & $\mathrm{Ca} 12$ & & $\sqrt{ }$ & & $\sqrt{ }$ \\
\hline Adjustment & Ca13 & $\sqrt{ }$ & & & $\sqrt{ }$ \\
\hline Scanning & $\mathrm{Ca} 14$ & $\sqrt{ }$ & & & \\
\hline Inspecting & Ca15 & $\sqrt{ }$ & $\sqrt{ }$ & & \\
\hline
\end{tabular}

evaluation methods mentioned earlier to evaluate the production chain complexity. These evaluation methods are compared and analysed to determine the differences between them. The layout of the women's clothing workshop is shown in Figure 5.

As shown in Figure 6, the machines found in the women's clothing sewing workshop mainly include the following types:

(a) Sewing machines: they are the most important machines in garment production, as shown in Figures 6(a) and 6(b)

(b) Instruments for ironing: they are used for flat ironing, shaping, and other operations, as shown in Figure 6(c)

(c) Special equipment: they are used to complete special sewing operations, such as sewing buttonholes, attaching sleeves, and pressing, as shown in Figures 6(d)-6(h)

Group A, which processes windbreakers (18SSF-1), is used as an example for evaluating the production process complexity. The cut pieces of women's windbreakers are shown in Table 4, where $J$ represents the machine labels. The machines are arranged in series: $J 1, J 2, \ldots, J 18(J 1-J 7$ represent the sewing machines or ironing equipment, and J8-J18 represent the special machines).

3.5. Evaluation Results of Method 1. According to Method 1, in the women's clothing sewing workshop A, with $m=96$, $n=28$, and $r=18$, the sewing production process chain complexity is calculated using (1) as follows:

$$
\begin{aligned}
C_{s 1} & =\log _{2} m^{2} \\
n r & =22.1472 .
\end{aligned}
$$

3.6. Evaluation Results of Method 2. The windbreaker (18SSF-1) production in the women's clothing workshop A is used as an example, and the standard operation time for sewing the windbreaker is shown in Table 5 .

According to Method 2, the sewing production process chain complexity is calculated using (2) as follows:

$$
C_{s 2}=-\sum_{j=1}^{M} \sum_{i=1}^{S_{j}} P_{i j} \log _{2} P_{i j}=6.80 .
$$

3.7. Evaluation Results of Method 3. Method 3 considers the processing and idle states of a machine. The sewing production process chain complexity can be calculated using (3) as follows:

$$
C_{s 3}=-\sum_{j=1}^{M} \sum_{i=1}^{S_{j}} P_{i j} \log _{2} P_{i j}=50.25 .
$$

3.8. Evaluation Results of Method 4. The sewing process is similar to the assembly process, and the cut pieces can be regarded as individual parts. Accordingly, the method proposed by Modrak and Zuzana [9] for evaluating manufacturing process chain complexity is used to present the process chain diagram of cut pieces using sewing equipment, as shown in Figure 7. Cut pieces are indicated by " ", sewing equipment is indicated by "," and the processing route of cut pieces is indicated by "." The cut piece is indicated by a solid line in the sewing equipment processing and by a dotted line in special machine processing. Taking 18SSF-1 as an example, its cut pieces comprise 28 pieces, including eight sleeve cut pieces $(X 1-X 8)$, six pocket cut pieces $(D 1-D 6)$, four front cut pieces $(Q 1-Q 4)$, two rear cut pieces (H1 and $H 2)$, four collar cut pieces (L1-L4), two hanging cut pieces ( $G 1$ and $G 2)$, and two belt cut pieces ( $Y 1$ and Y2). The processing of each cut piece needs to be 









FIGURE 5: Layout of the women's wear workshop.
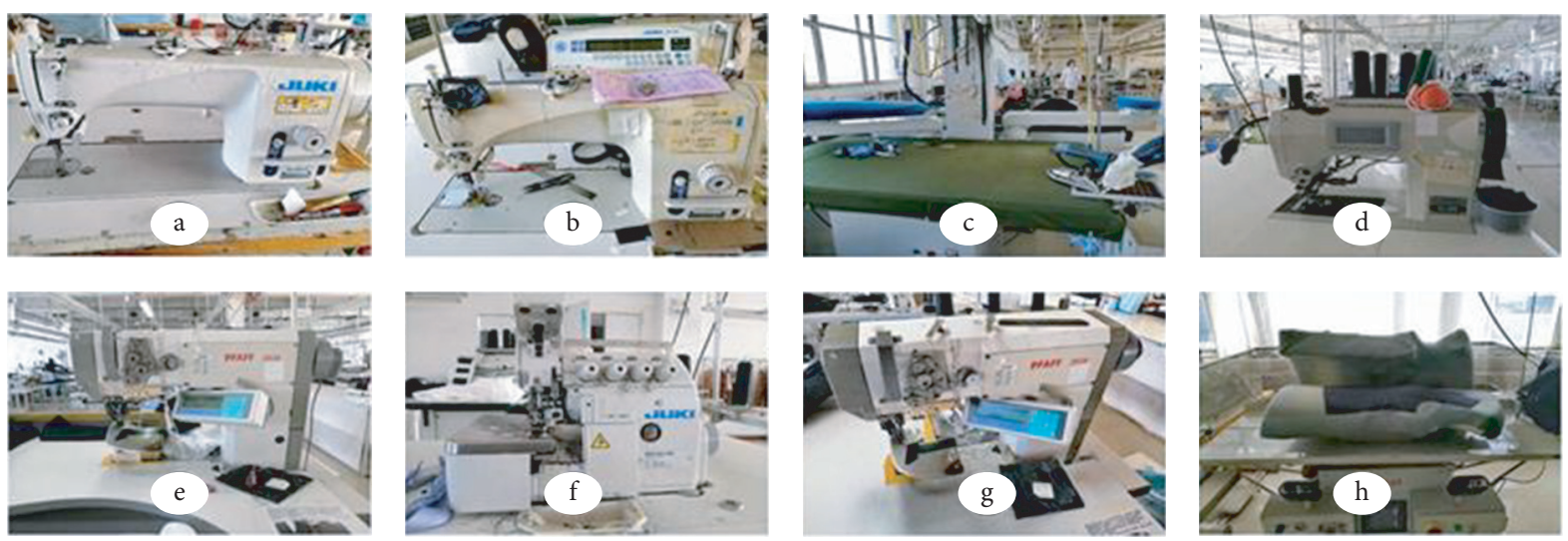

FIGURE 6: Sewing equipment in the women's clothing workshop.

completed using $J 1-J 18$ sewing equipment. We draw the process chain of each cut piece in each sewing equipment according to the cutting process and processing sequence. Taking the sleeve cut piece $X 1$ of $18 \mathrm{SSF}-1$ as an example, according to its process requirements, the processing of $X 1$ needs to be performed on the sewing equipment $J 2, J 1, J 6$, $J 12, J 10, J 3$, and $J 5$. The processing sequence is $\mathrm{J} 2 \longrightarrow \mathrm{J} 1 \longrightarrow \mathrm{J} 6 \longrightarrow \mathrm{J} 12 \longrightarrow \mathrm{J} 10 \longrightarrow \mathrm{J} 3 \longrightarrow \mathrm{J} 5 \longrightarrow \mathrm{J} 10 . \quad$ The process chain of cut piece $\mathrm{X} 1$ is drawn according to the processing sequence. Then, the process chains of all cut pieces are drawn using the same method. Consequently, the manufacturing process chain of $18 \mathrm{SSF}-1$ is formed.

The example shown in Figure 7 for cut piece $X 1$ has the following processing order: $\mathrm{J} 2 \longrightarrow \mathrm{J} 1 \longrightarrow \mathrm{J} 6 \longrightarrow \mathrm{J} 12$ $\longrightarrow \mathrm{J} 10 \longrightarrow \mathrm{J} 3 \longrightarrow \mathrm{J} 5 \longrightarrow \mathrm{J} 10$. These machines are all arranged in series, and the probability of each machine being used is equal, equal to $1 / 8$ (e.g., $P_{j 1}=1 / 8$ ). Therefore, the process static complexity of cut piece $X 1$ is calculated using (4) as follows:

$$
-\sum_{j=1}^{s} P_{j 1} \log _{2} P_{j i}=8 \times \frac{1}{8} \times \log _{2} \frac{1}{8}=3 .
$$

The production process static complexity of the other cut pieces is calculated similarly. The calculation results are shown in Table 6.

Based on (4), the production process chain static complexity for group A is calculated as follows:

$$
C_{s 4}=-\sum_{j=1}^{M} \sum_{i=1}^{N} P_{j k} \log _{2} P_{j k}=47.06 .
$$

\section{Results of Evaluating Production Process Chain Complexity considering Human Factors}

4.1. Perception Complexity Evaluation. The information entropy method is used to evaluate the perception complexity. The production characteristics and basic attributes of the resources required by sewing workers to complete the sleeve setting process are described in Table 7 .

The four product information variables in the information acquisition phase of the setting of the sleeve operation are as follows: $X 1=$ (three product variables: 
TABle 4: Type of cut pieces.

\begin{tabular}{lcc}
\hline No. & Type & Denotation \\
\hline 1 & Top sleeve (left) & $X 1$ \\
2 & Top sleeve (right) & $X 2$ \\
3 & Sleeve tab (left 1) & $X 3$ \\
4 & Sleeve tab (left 2) & $X 4$ \\
5 & Sleeve tab (right 1) & $X 5$ \\
6 & Sleeve tab (right 2) & $X 6$ \\
7 & Pocket flap (left 1) & $D 1$ \\
8 & Pocket flap (left 1) & $D 2$ \\
9 & Pocket flap (right 1) & $D 3$ \\
10 & Pocket flap (right 2) & $D 4$ \\
11 & Pocket (left) & $D 5$ \\
12 & Pocket (right) & $D 6$ \\
13 & Under sleeve (left) & $X 7$ \\
14 & Under sleeve (right) & $X 8$ \\
15 & Front piece 1 & $Q 1$ \\
16 & Front piece 2 & $Q 2$ \\
17 & Front piece 3 & $Q 3$ \\
18 & Front piece 4 & $Q 4$ \\
19 & Back piece 1 & $H 1$ \\
20 & Back piece 2 & $H 2$ \\
21 & Collar 1 & $L 1$ \\
22 & Collar 2 & $L 2$ \\
23 & Collar stand 1 & $L 3$ \\
24 & Collar stand 2 & $L 4$ \\
25 & Facing & $G 1$ \\
26 & Facing & $Y 2$ \\
27 & Waistband 1 & $Y 2$ \\
28 & Waistband 2 & \\
\hline & &
\end{tabular}

semifinished clothes, sleeves, and thread), $X 2=$ (four process variables: alignment, suturing, thread removal, and inspection), $X 3=$ (three tooling variables: sewing machine, scissors, and mannequins), and $X 4=$ (two workplace variables: workbench and mannequins' area).

The relationship matrix can be obtained from the information relationship diagram shown in Figure 8. Table 8 lists the relationships between the different information variables and the perception complexity results of the product information variables $(X 1)$. The method for evaluating the perception complexity of the other production information variables $(X 2, X 3$, and $X 4)$ is the same as that of $X 1$. The perception complexity of the $m$ th sewing process is obtained using equation (5)-(7) as follows:

$$
\begin{aligned}
C_{p m} & =-\sum_{j=1}^{4} \sum_{i=1}^{n_{j}} P_{i j} \log _{2} P_{i j} \\
& =1.584+1.984+1.52+1 \\
& =6.088 .
\end{aligned}
$$

4.2. Cognitive Complexity Evaluation. Take setting in sleeve process as an example, the operation of setting in sleeve is decomposed into 23 work steps. According to the secondgeneration human reliability analysis method, the type of cognitive activity and cognitive function are judged for each

\begin{tabular}{|c|c|}
\hline $\begin{array}{l}\text { Cut pieces } \\
\text { type }\end{array}$ & Standard machine operation time (min) \\
\hline$X 1$ & J2 (1.6), J3 (5), J5 (13.9), J6 (1.2), J13 (1.4), J11 (5.6) \\
\hline$X 2$ & $J 2(1.6), J 3(5), J 5(13.9), J 6(1.2), J 13(1.4), J 11$ (5.6) \\
\hline$X 3$ & $J 2(2), J 3(2.7), J 10(2.8), J 17(4.4), J 18(1.5)$ \\
\hline$X 4$ & $J 2(2), J 3(2.7), J 10(2.8), J 17(4.4), J 18$ (1.5) \\
\hline$X 5$ & $J 2(2), J 3(2.7), J 10(2.8), J 17(4.4), J 18$ (1.5) \\
\hline$X 6$ & $J 2(2), J 3(2.7), J 10(2.8), J 17(4.4), J 18$ (1.5) \\
\hline$D 1$ & $J 9(1.6), J 1(2.5), J 5(2.8)$ \\
\hline D2 & $J 9(1.6), J 1(2.5), J 5(2.8)$ \\
\hline D3 & $J 9$ (1.6), J1 (2.5), J5 (2.8) \\
\hline D4 & $J 9$ (1.6), J1 (2.5), J5 (2.8) \\
\hline D5 & $J 3(1.5), J 5(5.8), J 3(2.2)$ \\
\hline D6 & $J 3(1.5), J 5(5.8), J 3(2.2)$ \\
\hline$X 7$ & $J 2(1.6), J 6(1.2), J 12(1.4), J 11(5.6)$ \\
\hline$X 8$ & $J 2(1.6), J 6(1.2), J 12(1.4), J 11(5.6)$ \\
\hline Q1 & $J 2(5.4), J 3(1.9), J 12(1.4), J 11(5.6)$ \\
\hline Q2 & $J 2$ (5.4), J3 (1.9), J12 (1.4), J11 (5.6) \\
\hline Q3 & $J 2(5.4), J 4(1.2), J 16(4.8), J 11(5.6), J 3(1.9), J 4(3)$ \\
\hline Q4 & $J 2(5.4), J 4(1.2), J 16(4.8), J 11(5.6), J 3(1.9), J 4(3)$ \\
\hline$H 1$ & $J 6$ (2.5), J1(1.2), J11 (2.2), J15 (0.7) \\
\hline$H 2$ & $J 6(2.5), J 1(1.2), J 11(2.2), J 15(0.7)$ \\
\hline$L 1$ & J6 (1.8), J4 (5.65), J14 (1.5), J1 (1.5), J4 (6.5), J7 \\
\hline$L 2$ & J6 (1.8), J4 (5.65), J14 (1.5), J1 (1.5), J4 (6.5), J7 \\
\hline$L 3$ & $\begin{array}{c}J 6 \text { (1.8), J4 (5.65), J14 (1.5), J1 (1.5), J4 (6.5), J7 } \\
(2.5)\end{array}$ \\
\hline$L 4$ & $\begin{array}{c}J 6 \text { (1.8), J4 (5.65), J14 (1.5), J1(1.5), J4 (6.5), J7 } \\
(2.5)\end{array}$ \\
\hline G1 & $J 7$ (0.8), J4 (2.7), J1 (1.6) \\
\hline G2 & $J 7(0.8), J 4(2.7), J 1(1.6)$ \\
\hline$Y 1$ & $J 7(3.2), J 1(1.6), J 5(0.8)$ \\
\hline$Y 2$ & $J 7(3.2), J 1(1.6), J 5(0.8)$ \\
\hline
\end{tabular}

TABLE 5: Sewing process and machine operation time for women's garment (18SSF-1).

work step. The 23 work steps are analysed; when the work step belongs to cognitive activity, it is represented by " $\sqrt{ }$ "; the results as shown in Tables 9 and 10.

According to Tables 2, 3, 9, and 10, the cognitive complexity for setting the sleeve is then calculated by (8); the results are shown in Table 11.

$$
C_{c m}=-\sum_{f=1}^{4} P_{c o f} \log _{2} P_{c o f}=1.8516 .
$$

The sewing process of the women's windbreaker involves 96 processes. The same method as the one for setting the sleeves is adopted using (5) and (6). The perception complexity and cognitive complexity of each sewing process are calculated. The calculation results are summarised in Table 12

According to equations (10)-(13),

$$
\begin{aligned}
C_{l} & =C_{s 4}+\sum_{m=1}^{n_{p}} C_{p m}+\sum_{m=1}^{n_{c}} C_{c m} \\
& =47.06+224.269+165.072 \\
& =436.40 .
\end{aligned}
$$




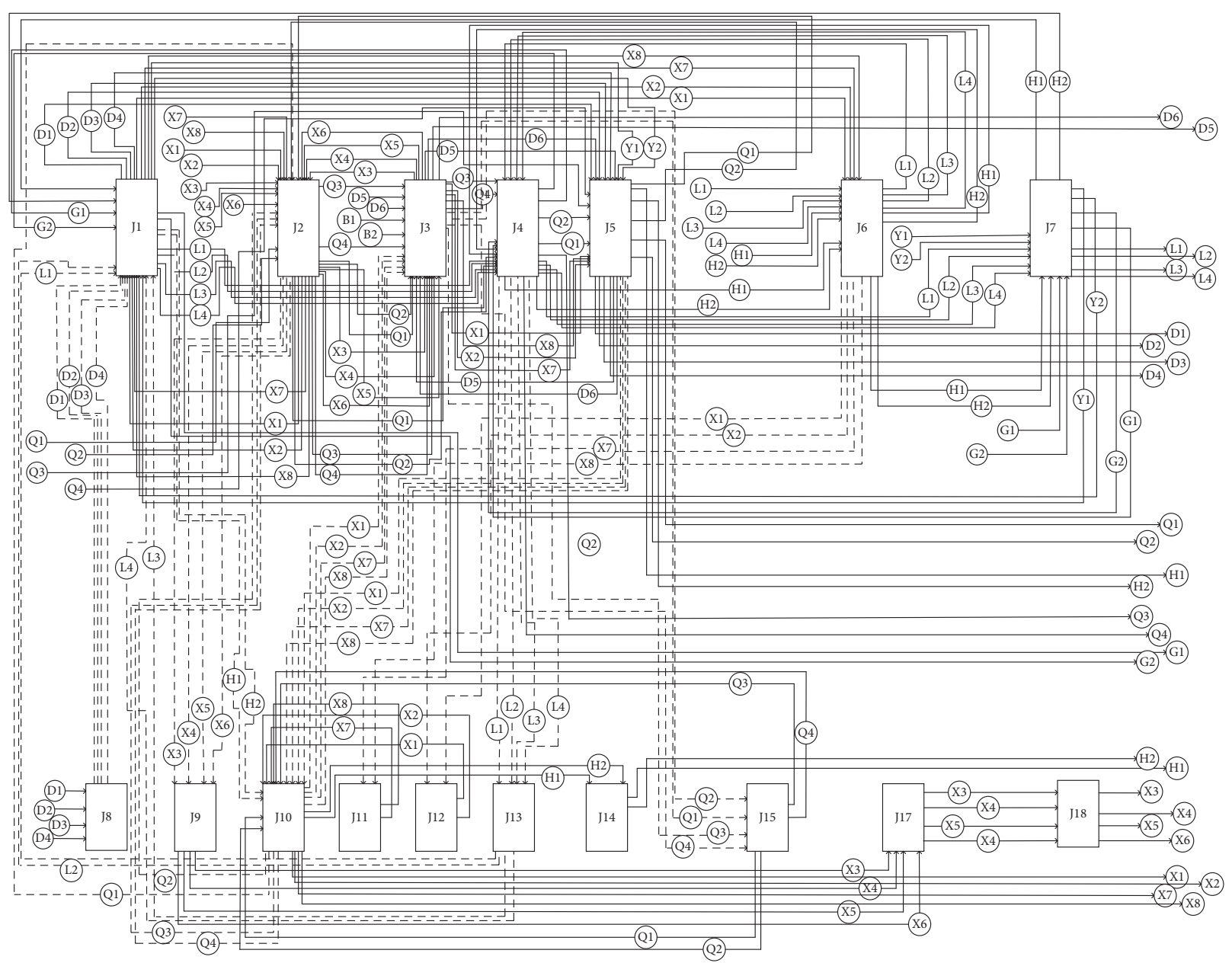

FIGURE 7: Manufacturing process chain of group A in women's clothing workshop.

TABLE 6: Static complexity of cut pieces.

\begin{tabular}{lcr}
\hline No. & Denotation & \\
\hline 1 & $X 1$ & $C_{s 4}$ \\
2 & $X 2$ & 3 \\
3 & $X 3$ & 2.3219 \\
4 & $X 4$ & 2.3219 \\
5 & $X 5$ & 2.3219 \\
6 & $X 6$ & 2.3219 \\
7 & $D 1$ & 1.585 \\
8 & $D 2$ & 1.585 \\
9 & $D 3$ & 1.585 \\
10 & $D 4$ & 1.585 \\
11 & $D 5$ & 1.585 \\
12 & $D 6$ & 1.585 \\
13 & $X 7$ & 2.8074 \\
14 & $X 8$ & 2.8074 \\
15 & $Q 1$ & 3 \\
16 & $Q 2$ & 3 \\
17 & $Q 3$ & 3.1699 \\
18 & $Q 4$ & 3.1699 \\
19 & $H 1$ & 3 \\
20 & $H 2$ & 3 \\
21 & $L 1$ & 2.585 \\
22 & $L 2$ & 2.585 \\
23 & $L 3$ & 2.585 \\
\hline & &
\end{tabular}


TABle 6: Continued.

\begin{tabular}{lcr}
\hline No. & Denotation & $C_{s 4}$ \\
\hline 24 & $L 4$ & 2.585 \\
25 & $G 1$ & 1.585 \\
26 & $G 2$ & 1.585 \\
27 & $Y 1$ & 1.585 \\
28 & $Y 2$ & 1.585 \\
\hline
\end{tabular}

TABLE 7: Description of the sleeve setting process.

\begin{tabular}{|c|c|c|}
\hline Classification & Element & Description \\
\hline Production characteristics & $\begin{array}{l}\text { System } \\
\text { Part } \\
\text { Process } \\
\text { Procedure }\end{array}$ & $\begin{array}{c}\text { Sewing } \\
\text { Sleeve, semifinished clothes } \\
\text { Setting in sleeve } \\
\text { Alignment, remove thread, suture, inspection }\end{array}$ \\
\hline Resources required & $\begin{array}{l}\text { Material } \\
\text { Person } \\
\text { Tool } \\
\text { Workplace }\end{array}$ & $\begin{array}{c}\text { Sleeve (one piece), semifinished clothes (one item), thread } \\
\text { Sewing worker (one person) } \\
\text { Sewing machine, scissors, mannequin } \\
\text { Bench, mannequin's area }\end{array}$ \\
\hline
\end{tabular}

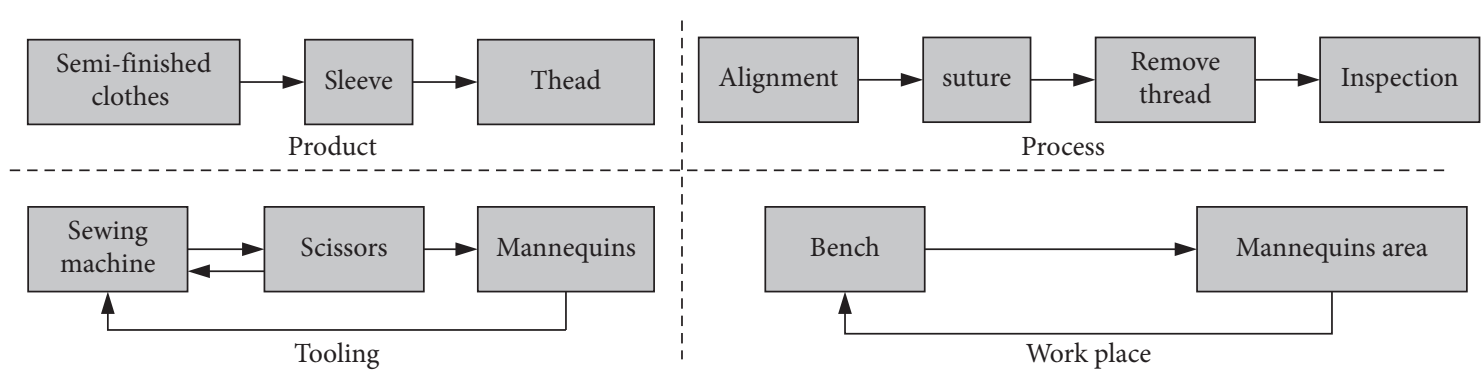

FIgURE 8: Four types of production information relationships of setting in sleeves.

TABLE 8: Perception complexity result of product information variables.

\begin{tabular}{|c|c|c|c|c|c|c|}
\hline \multirow{2}{*}{ Variables } & \multicolumn{3}{|c|}{ Relationship $R_{i}=(1,0)$} & \multirow{2}{*}{ Subtotal } & \multirow{2}{*}{$P_{i j}$} & \multirow{2}{*}{$-P_{i j} \log _{2} P_{i j}$} \\
\hline & Semifinished clothes & Sleeve & Thread & & & \\
\hline Semifinished clothes & 1 & 1 & 1 & 3 & 0.333 & 0.528 \\
\hline Sleeve & 1 & 1 & 1 & 3 & 0.333 & 0.528 \\
\hline Thread & 1 & 1 & 1 & 3 & 0.333 & 0.528 \\
\hline Total & & & & 9 & 1 & 1.584 \\
\hline
\end{tabular}

TABle 9: Cognitive activities (Ca1-Ca8) of setting in sleeve.

\begin{tabular}{|c|c|c|c|c|c|c|c|c|c|}
\hline No. & Working step & $\mathrm{Ca} 1$ & $\mathrm{Ca} 2$ & $\mathrm{Ca} 3$ & $\mathrm{Ca} 4$ & $\mathrm{Ca} 5$ & $\mathrm{Ca} 6$ & $\mathrm{Ca} 7$ & $\mathrm{Ca} 8$ \\
\hline 1 & Pick up the sleeve pieces & & & & & $\sqrt{ }$ & $\sqrt{ }$ & & \\
\hline 2 & Pick up bodice & & & & & $\sqrt{ }$ & $\sqrt{ }$ & & \\
\hline 3 & Inspect the cutting pieces & & & & & $\sqrt{ }$ & $\sqrt{ }$ & & \\
\hline 4 & Align the sleeve top and armhole & & & $\sqrt{ }$ & & $\sqrt{ }$ & & & \\
\hline 5 & Confirm alignment & & & & $\sqrt{ }$ & $\sqrt{ }$ & & & $\sqrt{ }$ \\
\hline 6 & Align sleeves and bodice & & & & & & $\sqrt{ }$ & & \\
\hline 7 & Align sleeve top and armhole & & & & & & $\sqrt{ }$ & & $\sqrt{ }$ \\
\hline 8 & Hold and sew sleeve top and armhole & & & & & & $\sqrt{ }$ & & $\sqrt{ }$ \\
\hline 9 & Move the sleeve and the bodice & & & & & & $\sqrt{ }$ & & \\
\hline 10 & Align and sew the sleeve and bodice & & & & & & $\sqrt{ }$ & & \\
\hline
\end{tabular}


TABle 9: Continued.

\begin{tabular}{|c|c|c|c|c|c|c|c|c|c|}
\hline No. & Working step & Cal & $\mathrm{Ca} 2$ & $\mathrm{Ca} 3$ & $\mathrm{Ca} 4$ & $\mathrm{Ca} 5$ & $\mathrm{Ca} 6$ & $\mathrm{Ca7}$ & $\mathrm{Ca} 8$ \\
\hline 11 & Remove the thread ends using scissors & & & & & $\sqrt{ }$ & $\sqrt{ }$ & & \\
\hline 12 & Hold and sew sleeve top and armhole & & & & & & $\sqrt{ }$ & & $\sqrt{ }$ \\
\hline 13 & Move the sleeve and armhole & & & & & & $\sqrt{ }$ & & \\
\hline 14 & Hold and sew the sleeve and armhole & & & & & & $\sqrt{ }$ & & $\sqrt{ }$ \\
\hline 15 & Move the sleeve and armhole & & & & & & $\sqrt{ }$ & & \\
\hline 16 & Hold and sew the sleeve and armhole & & & & & & $\sqrt{ }$ & & $\sqrt{ }$ \\
\hline 17 & Move the sleeve and the bodice & & & & & & $\sqrt{ }$ & & \\
\hline 18 & Hold and sew the sleeve and armhole & & & & & & $\sqrt{ }$ & & \\
\hline 19 & Remove the thread ends using scissors & & & & & $\sqrt{ }$ & $\sqrt{ }$ & & \\
\hline 20 & Hold and sew the sleeve and armhole & & & & & & $\sqrt{ }$ & & $\sqrt{ }$ \\
\hline 21 & Remove the sleeve and bodice & & & & & & $\sqrt{ }$ & & \\
\hline 22 & Inspect the cutting pieces & & & & & $\sqrt{ }$ & $\sqrt{ }$ & & \\
\hline 23 & Inspection & & & & & & $\sqrt{ }$ & & \\
\hline
\end{tabular}

Table 10: Cognitive activities (Ca9-Ca15) of setting in sleeve.

\begin{tabular}{|c|c|c|c|c|c|c|c|c|}
\hline No. & Working step & $\mathrm{Ca} 9$ & Ca10 & Ca11 & Ca12 & Ca13 & Ca14 & Ca15 \\
\hline 1 & Pick up the sleeve pieces & & $\sqrt{ }$ & & & & & \\
\hline 2 & Pick up bodice & & $\sqrt{ }$ & & & & & \\
\hline 3 & Inspect the cutting pieces & & $\sqrt{ }$ & & & & & \\
\hline 4 & Align the sleeve top and armhole & & $\sqrt{ }$ & & & $\sqrt{ }$ & & $\sqrt{ }$ \\
\hline 5 & Confirm alignment & & & & & & & $\sqrt{ }$ \\
\hline 6 & Align sleeves and bodice & & & & & $\sqrt{ }$ & & \\
\hline 7 & Align sleeve top and armhole & & & & & $\sqrt{ }$ & & \\
\hline 8 & Hold and sew sleeve top and armhole & & & & & $\sqrt{ }$ & & \\
\hline 9 & Move the sleeve and the bodice & & & & & $\sqrt{ }$ & & \\
\hline 10 & Align and sew the sleeve and bodice & & & & & $\sqrt{ }$ & & \\
\hline 11 & Remove the thread ends using scissors & & $\sqrt{ }$ & & & & & \\
\hline 12 & Hold and sew sleeve top and armhole & & & & & $\sqrt{ }$ & & \\
\hline 13 & Move the sleeve and armhole & & & & & $\sqrt{ }$ & & \\
\hline 14 & Hold and sew the sleeve and armhole & & & & & $\sqrt{ }$ & & \\
\hline 15 & Move the sleeve and armhole & & & & & $\sqrt{ }$ & & \\
\hline 16 & Hold and sew the sleeve and armhole & & & & & $\sqrt{ }$ & & \\
\hline 17 & Move the sleeve and the bodice & & & & & $\sqrt{ }$ & & \\
\hline 18 & Hold and sew the sleeve and armhole & & & & & $\sqrt{ }$ & & \\
\hline 19 & Remove the thread ends using scissors & & $\sqrt{ }$ & & & & & \\
\hline 20 & Hold and sew the sleeve and armhole & & & & & $\sqrt{ }$ & & \\
\hline 21 & Remove the sleeve and bodice & & & & & & & \\
\hline 22 & Inspect the cutting pieces & & $\sqrt{ }$ & & & & & $\sqrt{ }$ \\
\hline 23 & Inspection & & & & & & & $\sqrt{ }$ \\
\hline
\end{tabular}

TABLE 11: Cognitive complexity of setting in sleeve.

\begin{tabular}{lccccc}
\hline \multirow{2}{*}{ Cognitive activity } & \multicolumn{2}{c}{ Cognitive function } & Total \\
& Observation $(f=1)$ & Explanation $(f=2)$ & Plan $(f=3)$ & Execution $(f=4)$ & 97 \\
\hline $\mathrm{CO}_{f}$ & 25 & 14 & 16 & 42 & 0.4331 \\
$P_{\text {cof }}$ & 0.2577 & 0.1443 & 0.1649 & 1 \\
$-P_{\text {cof } \log _{2} P_{\text {cof }}}$ & 0.5030 & 0.4030 & 0.4228 & 0.5228 & 1.8516 \\
\hline
\end{tabular}

The evaluation results show that Method 1 considers the machines, parts, and operations in the production process. Method 2 considers the machines and operations. Method 3 considers machines and parts and operations. Method 4 considers machines, operations, and processing sequence of parts. And method 5 (proposed in this study) incorporates the human factors based on Method 4, as shown in Table 13. With the addition of the human factors, the complexity of the production process chain increases significantly. This indicates that human cognitive and perceived complexities 
TABLE 12: Calculation results of perception complexity and cognitive complexity.

\begin{tabular}{|c|c|c|c|}
\hline No. & Sewing process & $C_{p m}$ & $C_{c m}$ \\
\hline 1 & Pressing flap & 2 & 1.6072 \\
\hline 2 & Pressing elbow seam & 2 & 1.7445 \\
\hline 3 & Pressing shoulder seam & 2 & 1.6336 \\
\hline 4 & Pressing facing & 2 & 1.7824 \\
\hline 5 & Folding sleeve hem & 2.584 & 1.4956 \\
\hline 6 & Pressing gorge line & 2.584 & 1.6753 \\
\hline 7 & Pressing back vent & 2.584 & 1.4956 \\
\hline 8 & Pressing inseam & 2 & 1.7592 \\
\hline 9 & Sewing collar & 2.584 & 1.6067 \\
\hline 10 & Pressing sleeve triangle* 2 & 2 & 1.6506 \\
\hline 11 & Folding facing interlining & 2.584 & 1.4956 \\
\hline 12 & Check waistband & 2 & 1.6072 \\
\hline 13 & Pressing back & 2 & 1.7824 \\
\hline 14 & Pressing collar & 2 & 1.6506 \\
\hline 15 & Pressing waistband & 2 & 1.6753 \\
\hline 16 & Check collar & 2 & 1.7660 \\
\hline 17 & Pressing collar stand & 2 & 1.6506 \\
\hline 18 & Sewing waistband mouth reserved & 2.584 & 1.7469 \\
\hline 19 & Marking front edge & 3.186 & 1.6067 \\
\hline 20 & Top-stitching sleeve tab & 2 & 1.8009 \\
\hline 21 & Top-stitching front seam & 2 & 1.8009 \\
\hline 22 & Joining elbow seam & 2 & 1.8009 \\
\hline 23 & Joining inseam & 2 & 1.8009 \\
\hline 24 & sewing front edge & 2 & 1.7982 \\
\hline 25 & Binding elbow seam & 2.584 & 1.7469 \\
\hline 26 & Binding inseam and cuff & 2.584 & 1.7469 \\
\hline 27 & Basting front piece & 2 & 1.7469 \\
\hline 28 & Top-stitching elbow seam & 2 & 1.8099 \\
\hline 29 & Binding hem & 2.584 & 1.7634 \\
\hline 30 & Attaching brand & 3.186 & 1.5513 \\
\hline 31 & Stitching sleeve tab & 2.584 & 1.5513 \\
\hline 32 & Joining front seam & 2 & 1.8099 \\
\hline 33 & Sewing hem $1 / 6$ & 2.584 & 1.7982 \\
\hline 34 & Pressing sleeve tab & 2.584 & 1.6655 \\
\hline 35 & Marking patch pocket position & 3.186 & 1.5513 \\
\hline 36 & Blocking front piece & 2 & 1.6655 \\
\hline 37 & Sewing cuff & 3.186 & 1.7982 \\
\hline 38 & Sewing flap & 2 & 1.7660 \\
\hline 39 & Pressing side seam & 2 & 1.7592 \\
\hline 40 & Pressing front seam & 2 & 1.7824 \\
\hline 41 & Sewing patch pocket up side & 2 & 1.7982 \\
\hline 42 & Making French tack & 2 & 1.5513 \\
\hline 43 & Pressing patch pocket up side & 2 & 1.6655 \\
\hline 44 & Check the front edge & 2.584 & 1.7660 \\
\hline 45 & Sewing hem $3 / 6$ & 3.186 & 1.7982 \\
\hline 46 & Pressing patch pocket & 3.186 & 1.6655 \\
\hline 47 & Pressing front edge & 2 & 1.6072 \\
\hline 48 & Marking armhole position & 2.584 & 1.6067 \\
\hline 49 & Stitching flap & 3.186 & 1.7838 \\
\hline 50 & Top collar stitching & 2 & 1.8099 \\
\hline 51 & Joining shoulder seam & 2 & 1.5450 \\
\hline 52 & Sewing facing & 2 & 1.7982 \\
\hline 53 & Basting collar & 2.584 & 1.7469 \\
\hline 54 & Sewing collar on and down & 5.1550 & 1.8516 \\
\hline 55 & Joining facing & 2 & 1.5450 \\
\hline 56 & Marking collar stand & 2.584 & 1.6067 \\
\hline 57 & Binding armhole & 2.584 & 1.8118 \\
\hline 58 & Ticking collar & 3.186 & 1.7952 \\
\hline 59 & Sewing collar stand & 2.584 & 1.7952 \\
\hline 60 & Sewing hem 1/6 & 3.186 & 1.7982 \\
\hline
\end{tabular}


TABLE 12: Continued.

\begin{tabular}{|c|c|c|c|}
\hline No. & Sewing process & $C_{p m}$ & $C_{c m}$ \\
\hline 61 & Bundling armhole & 2 & 1.6506 \\
\hline 62 & Attaching pocket to garment & 2 & 1.7982 \\
\hline 63 & Basting armhole & 2 & 1.7469 \\
\hline 64 & Top-stitching flap & 2 & 1.8009 \\
\hline 65 & Attaching flap & 2.584 & 1.7660 \\
\hline 66 & Making waistband clip & 2 & 1.6655 \\
\hline 67 & Stitching patch pocket mouth & 2.584 & 1.7982 \\
\hline 68 & Top-stitching flap mouth & 2 & 1.8009 \\
\hline 69 & Basting and stitching patch pocket & 2 & 1.7469 \\
\hline 70 & Setting in sleeve & 6.088 & 1.8516 \\
\hline 71 & Cutting flap & 2.584 & 1.7660 \\
\hline 72 & Joining back seam & 2.584 & 1.8099 \\
\hline 73 & Basting side facing interlining & 2.584 & 1.7469 \\
\hline 74 & Joining back center seam & 2 & 1.8099 \\
\hline 75 & Top-stitching back seam & 2 & 1.8099 \\
\hline 76 & Sewing side seam & 2 & 1.8099 \\
\hline 77 & Binding back seam & 2.584 & 1.7469 \\
\hline 78 & Basting side facing interlining & 2 & 1.7469 \\
\hline 79 & Binding side seam & 2.584 & 1.7469 \\
\hline 80 & Stitching sleeve triangle ${ }^{*} 2$ & 2 & 1.7982 \\
\hline 81 & Cutting collar & 2.584 & 1.7660 \\
\hline 82 & Sewing wash care label & 2 & 1.8092 \\
\hline 83 & Top-stitching back center seam & 2 & 1.7982 \\
\hline 84 & Cutting collar stand & 2 & 1.7660 \\
\hline 85 & Top-stitching back vent & 2 & 1.7982 \\
\hline 86 & Binding back seam & 2.584 & 1.7469 \\
\hline 87 & Basting waistband & 2 & 1.7982 \\
\hline 88 & Top-stitching waistband & 2 & 1.8099 \\
\hline 89 & Identifying and bundling & 2 & 1.5513 \\
\hline 90 & Sewing buttonhole of sleeve tab* 4 & 3 & 1.4200 \\
\hline 91 & Sewing hem $1 / 6$ & 2.584 & 1.7982 \\
\hline 92 & Sewing buttonhole of front edge ${ }^{*} 5$ & 3 & 1.4200 \\
\hline 93 & Edging facing & 2 & 1.7660 \\
\hline 94 & Sewing back vent & 2.584 & 1.7982 \\
\hline 95 & Pressing collar stand & 2 & 1.6506 \\
\hline 96 & Pressing hanging loop & 2.584 & 1.6655 \\
\hline & Total & 224.269 & 165.072 \\
\hline
\end{tabular}

TABLE 13: Comparison of five production chain complexity evaluation methods.

\begin{tabular}{lccccc}
\hline Evaluation items/results & Method 1 & Method 2 & Method 3 & Method 4 & Method 5 \\
\hline Machines & $\sqrt{ }$ & $\sqrt{ }$ & $\sqrt{ }$ & $\sqrt{ }$ & $\sqrt{ }$ \\
Parts & $\sqrt{ }$ & - & $\sqrt{ }$ & - & $\sqrt{ }$ \\
Operations & $\sqrt{ }$ & - & - & $\sqrt{ }$ & $\sqrt{ }$ \\
Processing sequences & - & - & - & $\sqrt{ }$ & 47.06 \\
Human factors & 22.15 & 6.80 & 50.25 & $\sqrt{ }$ \\
$C_{l}$ & & & & 436.40 \\
\hline
\end{tabular}

account for a large proportion. Therefore, human factor complexity cannot be omitted.

\section{Conclusions, Discussion, and Future Studies}

5.1. Conclusions and Discussion. Sewing operations are highly dependent on the workers. During the sewing process, cognition and perception complexities have an impact on weaving efficiency and garment quality. In this study, complexity theory is applied to garment production. A new evaluation method of the production process chain complexity considering human factors is proposed. Based on the quantitative results of human factor complexity shown in Table 12, changes in perceived complexity and cognitive complexity are not necessarily synchronous. That is, for any process, if the perceived complexity is high, then the cognitive complexity is not necessarily high, and vice versa. However, for processes with relatively complex sewing 
processes and difficult operations, such as setting in sleeves, the perceived complexity and cognitive complexity are relatively high. Meanwhile, if the operation time of a sewing process is long, its perceptual complexity and cognitive complexity are not necessarily high. For example, the operation time of ironing bag covers is $150 \mathrm{~s}$, and its perceptual complexity is 2 , whereas the operation time of cufflink folding is $36 \mathrm{~s}$ and its perceived complexity is 2.584 . Based on the comparative analysis results in Table 13 , the complexity of the production and manufacturing process chains significantly increases when human factors are considered. The proposed evaluation method is very useful for the complexity evaluation of the production process chain, especially for manual manufacturing systems. Furthermore, factors in the manufacturing process, such as machines, parts, operation, and human factors, are all considered in the proposed method. Human factors are particularly described in detail.

5.2. Future Studies. From this analysis, the proposed evaluation method provides theoretical support and evaluation tools for garment shops. Although this study did not investigate how complexity affects weaving system efficiency and product quality, the proposed method provides an algorithm tool for further research in this field. Vidal and Hernandez [28] argued that it is necessary to reduce complexity in manufacturing systems. In future studies, we shall focus on reducing the complexity of sewing production chains using mathematical modelling, simulations, and other methods to improve production efficiency and reduce the defect rate. [22].

\section{Data Availability}

The data that support the findings of this study are available from (third party) (W\&F Bird Group co.,Ltd.). Restrictions apply to the availability of these data, which were used under license for this study. Data are available from http:// user52060.nz86.com/.

\section{Conflicts of Interest}

The authors do not have any conflicts of interest to declare regarding the publication of this paper.

\section{Acknowledgments}

The authors also would like to thank Jilin W\&F Bird Group Co., Ltd., for allowing the use of the research sites. This study was supported by the Scientific and Technological Development Plan of Jilin Provincial Science and Technology Department (Grant ID 2020122355JC).

\section{References}

[1] G. J. Klir, "Complexity: some general observations," Systems Research, vol. 2, no. 2, pp. 131-140, 1985.

[2] G. Frizelle and E. Woodcock, "Measuring complexity as an aid to developing operational strategy," International Journal of Operations \& Production Management, vol. 15, no. 5, pp. 26-39, 1995.
[3] F. Isik, "Complexity in supply chains: a new approach to quantitative measurement of the supply-chain-complexity," Supply Chain Management, vol. 4, pp. 417-432, 2011.

[4] T. Guimaraes, N. Martensson, and J. Stahre, "Empirically testing the impact of manufacturing system complexity on performance," International Journal of Operations \& Production Management, vol. 19, no. 12, pp. 1254-1269, 1999.

[5] S. Kekre and K. Srinivasan, "Broader product line: a necessity to achieve success?" Management Science, vol. 36, pp. 1216-1232, 199.

[6] J. P. MacDuffie, K. Sethuraman, and M. L. Fisher, "Product variety and manufacturing performance: evidence from the international automotive assembly plant study," Management Science, vol. 42, no. 3, pp. 350-369, 1996.

[7] N. P. Suh, Complexity: Theory and Applications, Oxford University Press, 2005.

[8] A. V. Deshmukh, Complexity and Chaos in Manufacturing Systems, Ph.D. Thesis, Purdue University, IN, USA, 1993.

[9] V. Modrak and Z. Zuzana, "Novel complexity indicator of manufacturing process chains and its relations to indirect complexity indicators," Complexity, vol. 2017, Article ID 9102824, 15 pages, 2017.

[10] Z. Zhang, "Manufacturing complexity and its measurement based on entropy models," International Journal of Advanced Manufacturing Technology, vol. 62, no. 9-12, pp. 867-873, 2012.

[11] Z. Zhang, F. Xie, and R. Xiao, "Study on complexity of cellular manufacturing based on state entropy models," China Mechanical Engineering, vol. 19, pp. 2332-2336, 2009.

[12] T. Fässberg, F. Hellman, A. Davidsson, and J. Stahre, "Relations between complexity, quality and cognitive automation in mixed-model assembly," Journal of Manufacturing Systems, vol. 32, no. 3, pp. 449-455, 2013.

[13] H. Schleich, L. Schaffer, and F. Scavarda, "Managing complexity in automotive production," in Proceedings of the 19th international conference on production research, Chile, USA, July 2007.

[14] C. Falck, R. Örtengren, M. Rosenqvist, and R. Söderberg, "Basic complexity criteria and their impact on manual assembly quality in actual production impact on manual assembly quality," International Journal of Industrial Ergonomics, vol. 58, pp. 117-128, 2017.

[15] F. He, Y. Rao, C. Zhang, and X. Shao, "Evelopment of the complexity measure for assembly line systems using entropy concept," in Proceedings of the 7th World Congress on Intelligent Control and Automation, pp. 25-27, Chongqing, China, June 2008.

[16] X. W. Zhu, D. Vera, Y. Koren, and S. P. Marin, "Modeling of manufacturing complexity in mixed-model assembly lines," Procedia CIRP, vol. 130, no. 5, pp. 1-10, 2008.

[17] M. F. Alkan, V. Daniel, M. Ahmad, B. Schubö, and R. Harrison, "A model for complexity assessment in manual assembly operations through predetermined motion time systems," Procedia, CIRP, vol. 44, no. 4-5, pp. 429-434, 2016.

[18] M. F. Zaeh, R. Grotenhuis, A. R. van Goor, and A. Schbo, "Assessing complexity of supply chains: evidence from wholesalers," International Journal of Operations \& Production Management, vol. 3, pp. 489-496, 2009.

[19] A. D. Leeuw, J. V. Goor, A. Schatz, and T. Bauernhansl, "Evaluation of complexity management systems - systematical and maturity-based approach," International Journal of Operations and Production Management, vol. 33, no. 8, pp. 960-980, 2013. 
[20] H. Kluth, S. Jäger, A. Schatz, and T. Bauernhansl, "Evaluation of complexity management systems - systematical and maturity-based approach," Procedia CIRP, vol. 17, pp. 224-229, 2014.

[21] K. Theuer, T. Lass, and F. au, "Mastering complexity with autonomous production processes," International Journal of Computer Integrated Manufacturing, vol. 52, no. 2, pp. 41-45, 2016.

[22] K. Windt, T. Philipp, and F. Böse, "Complexity cube for the characterization of complex production systems," International Journal of Computer Integrated Manufacturing, vol. 21, pp. 195-200, 2008.

[23] A. V. Brinzer and K. Schneider, "Complexity assessment in production: linking complexity drivers and effects," Procedia CIRP, vol. 93, no. 7, pp. 694-699, 2020.

[24] A. V. Deshmukh, J. J. Talavage, and M. M. Barash, "Complexity in manufacturing systems, Part 1: analysis of static complexity," IIE Transactions, vol. 30, pp. 645-655, 1998.

[25] F. Calinescu, Manufacturing Complexity - an Integrated Information Theoretic Approach, Dissertation. University of Oxford. Thesis, University of Oxford, Oxford, England, 2002.

[26] F. S. Kong, "Development of metric method and framework model of integrated complexity evaluations of production process for ergonomics work stations," International Journal of Production Research, vol. 57, pp. 2429-2445, 2018.

[27] What Is Perceived as Complex in Final Assembly?, Department of Product and Production Development Chalmers university of technology Gothenburg, no. 3-4, Gothenburg, Sweden, 2013.

[28] G. H. Vidal and J. R. C. Hernandez, "Complexity in manufacturing systems: a literature review," Production Engineering, vol. 15, pp. 321-333, 2021. 